\title{
Editorial
}

\section{Sustainable Mobility: Interdisciplinary Approaches}

\author{
Henrike Rau ${ }^{1, *}$ and Joachim Scheiner ${ }^{2}$ (D) \\ 1 Department of Geography, LMU Munich, 80333 München, Germany \\ 2 Department of Transport Planning, Faculty of Spatial Planning, Technische Universität Dortmund, \\ 44227 Dortmund, Germany; joachim.scheiner@tu-dortmund.de \\ * Correspondence: henrike.rau@geographie.uni-muenchen.de
}

Received: 15 November 2020; Accepted: 15 November 2020; Published: 30 November 2020

The continuous growth in greenhouse gas emissions from the transport sector has led to calls for a sustainability transition that is largely driven by technological means and supply-side measures such as infrastructure and vehicles. New engine technologies, 'clean' fuels, 'smart' mobilities and autonomous driving are some of the prominent topics that dominate transport research and policy today. However, equally important issues such as why people move in daily life the way they do, how mobility is linked to societal norms, expectations, and aspirations for the future, and what it implies for the natural environment remain under-explored, despite their close links to transport-related (un)sustainability. These knowledge gaps can be partly attributed to the persistent marginalization of social scientific perspectives and the dominance of individualistic approaches in transport research, at least until recently. This is surprising given that transport studies appear to be ideally suited for interdisciplinary inquiry because there is no longstanding theoretical tradition in the field from which a unifying core can be drawn and which brings about a certain resistance to (ex)change that is typical for more established and institutionalized disciplines.

The concept of sustainable mobility, that is, people moving in ways that are socially just, environmentally responsible, and economically viable, has also gained traction in research, policy, and public life. The launch of the International Journal of Sustainable Transportation in 2007 and numerous special issues on sustainable urban and rural transport across a broad spectrum of academic journals exemplify this trend (e.g., Special Issues in Sustainability on topics such as The Current and Future Role of Public Transport in Delivering Sustainable Cities, 2016, ed. Wijnand Veeneman and Eefje Cuppen; Sustainability Issues in Road Construction and Use, 2020, ed. Antonio D'Andrea or Sustainable Automobilities in the Mobile Risk Society, 2020, ed. Sven Kesselring). Importantly, the complexity of sustainability issues more generally, and sustainable mobility in particular, has drawn attention to the limitations of more narrow disciplinary inquiries, resulting in calls for greater interdisciplinarity and the adjustment of common impact assessment criteria to capture the benefits of inter- and transdisciplinary research (see [1] for a detailed discussion of issues of impact in the context of interdisciplinary sustainability research). Targeted funding opportunities are an essential ingredient of successful interdisciplinary collaboration in research. Examples include recent funding programs provided by the German Federal Ministry of Education and Research to support research on sustainable mobility (https://www.zukunft-nachhaltige-mobilitaet.de/projekte/, accessed 12 November 2020).

Responding to the limitations of (sustainable) transport and mobility studies that are confined to a single discipline, there is now a discernible shift towards interdisciplinary inquiry in transport and mobility research, a fact that this special issue aims to capture. Recent work links travel demand and transport planning to other fields such as public health [2,3], gender [4,5], environmental and transport fairness [6,7], spatiotemporal accessibility and the debates associated with it [8,9], and sustainable consumption. Recent publications on the 'consumption of distance' [10] and 'transport growth' [11] demonstrates the potential of connecting hitherto disparate disciplinary fields (e.g., transport and mobility studies and the sociology of consumption) and discipline-specific themes (mobility and 
consumption), with a view to creating synergies and identifying gaps and (in)compatibilities. Similarly, studies that look at variations in travel demand across the life course have begun to link spatial, social, economic and psychological perspectives [12,13].

However, the scope and nature of interdisciplinary mobility research remains the subject of intense debate, especially regarding the level of integration across disciplinary boundaries and the methodological choices required. For example, Miles et al. provide an interesting set of reflections on the merits and pitfalls of interdisciplinary transport research, drawing on their previous involvement in the UK-based Step-Change project, a five-year collaboration of transport engineers, mathematicians and social scientists intended to initiate a paradigmatic shift in the conceptualization and investigation of travel behavior changes [14]. Given the dominance to date of quantitative methodologies in transport and mobility studies, the latter issue seems particularly pertinent (see Scheiner and Rau [13] for an upcoming edited collection on the subject of quality and quantity in mobility biographies research).

This Special Issue of Sustainability titled 'Sustainable Mobility: Interdisciplinary Approaches' captures current trends in interdisciplinary mobility research, focusing in particular on methodological innovation and recent advances in bringing together researchers from different disciplines and critical perspectives on disciplinary divisions in mobility research. Furthermore, all contributions to this Special Issue explicitly capture the benefits and challenges of interdisciplinary forms of inquiry in the area of transport and mobility research. In particular, they offer a rich and diverse set of studies that demonstrate what this type of work across disciplinary boundaries looks like in practice.

A number of contributions to this special issue attend to the possibility of creating car-free cities and neighborhoods through deliberate planning and targeted policy initiatives that extend beyond existing disciplinary and administrative boundaries (Contribution 1,2). Johansson et al. (Contribution 1 ) analyze the impact of parking restrictions and the parallel provision of subsidized mobility services (e.g., car and bike sharing, free public transport passes) on the mobility practices of residents in two newly constructed apartment blocks in the greater Stockholm area. Their longitudinal, mixed-methods study recorded people's mobility practices before and after moving, with a view to capturing periods of both rapid change and apparent stagnation. Importantly, their commitment to theory-led empirical research produced rich results that are relevant to mobility researchers from different disciplines as well as planning professionals in Sweden and beyond.

Selzer and Lanzendorf's planning-critical study of car-free neighborhoods in Darmstadt (Germany) aptly demonstrates the need for cross-disciplinary collaboration and integration in research and urban and transport planning practice (Contribution 2). At the same time, it captures the opportunities and challenges that arise when conducting transdisciplinary research across the science-society spectrum. Using two case studies of car-reduced neighborhoods in Darmstadt (Germany), their contribution reveals how a narrative of car-free living can in fact reinforce the hegemony of the car in a predominantly automobile society and, at the same time, clash with the lived realities of local residents. It also demonstrates how the emergence of competing narratives shapes and reflects (un)certainties regarding the 'success' of sustainable transport initiatives.

Two other contributions complement these studies of car-free neighborhoods by providing interdisciplinary reflections on the reasons for people's mobility practices, including their use of different dominant and marginalized transport modes (Contribution 3,4). While not explicitly focused on car-free neighborhoods, Schwedes and Hoor's work also adopts a planning-critical approach to challenge dominant variants of integrated transport planning that are largely top down and supply-driven (Contribution 3). Their bottom-up, demand-oriented research provides interesting insights into the mobility needs of two groups of households in Germany's capital city Berlin, explicitly addressing the social and ecological sustainability goals of integrated transport planning in the process. Importantly, their innovative interdisciplinary inquiry reveals how different structural constraints prevent the final move away from the car, even in cases where people are willing to give up private automobility. This, in turn, has considerable implications for the availability and use of urban space, including spatial resources used for parking and charging electric cars. Overall, 
Schwedes and Hoor's reflections demonstrate the benefits of people-centered forms of inquiry that move beyond narrow disciplinary traditions associated with 'predict-and-provide' transport planning (Contribution 3).

Daramy-Williams et al. ask why car use is so resistant to attempts to change. Crossing disciplinary boundaries, they draw on the monograph 'Intention' by the philosopher Elizabeth Anscombe and the mobility biography literature to investigate the extent to which car use is habitual (Contribution 4). They ask whether it is cognitive inertia, or a matter of intentional choice rooted in people's expert knowledge of their own life situation that can explain the deeply entrenched nature of car use. Challenging this dichotomy, these authors argue that even habitual action may be intentional. Their theoretical considerations point to the fact that an individualistic conception of decision-making obscures the importance of people's situatedness that includes-in the transport field and elsewhere-their exposure to different infrastructure. This shift in perspective also promotes a broader view of what policy makers can do to change the transport system.

Interdisciplinary inquiries into transport and mobility issues that affect (sub)populations in the global South also feature prominently in this issue (Contribution 5,6). Jiron and Carrasco employ a mixed-methods approach to study people's embedded, emplaced and embodied mobility strategies in Concepción, Chile (Contribution 5). They combine an ethnographic mobile method ('shadowing' people on their trips and collaboratively reflecting on their experience) with a quantitative time use and social networks approach to activity-travel behavior. This complex exercise enables the authors to capture both individual behavior and interdependent coordination processes between networks of people and things. Treating mobility practices as the outcome of complex chains of decisions, many of which reflect people's social, cultural and material circumstances, broadens the scope of research and policy beyond disciplinary boundaries and conventional understandings of mobility.

Hidayati et al. bring together their collective expertise in the spatial and environmental sciences to conduct a socio-spatial analysis of path dependencies in Greater Jakarta's transport and land use system, making visible existing and emerging patterns of mobility inequality in the process (Contribution 6). Their multi-pronged, mixed-method study effectively combines current and historical data to show that previous policies have had a long-term impact on socio-spatial structures, including a gradual reduction in walkability and a parallel promotion of car use. At the same time, these policies have contributed to the establishment and amplification of mobility inequalities that disproportionately affect women, children and the elderly.

Some contributions to this special issue also reflect explicitly on the role of shared conceptual and methodological tools in facilitating successful interdisciplinary collaboration and exchange in the field of mobility research (Contribution 7,8,9). Lejoux et al. provide rich evidence of the advantages and limitations of an interdisciplinary inquiry carried out in France that focuses on coworking and its links with mobility and sustainability (Contribution 7). Their article reveals how an initial exchange between contributing partners with different disciplinary backgrounds is needed to make visible and creatively utilize the co-existence of diverse (and potentially divergent) meanings attached to key concepts such as mobility and sustainability. Moreover, Lejoux et al. demonstrate the necessity of debating methodological preferences and choices in a transparent and open manner and of dedicating extra time to interdisciplinary mobility research (Contribution 7).

Feldhoff et al. critically examine a concrete example of interdisciplinary knowledge integration (Contribution 8). Their contribution shows how a shared conceptual framework that revolves around the notion of a 'boundary object' and collective use of a particular methodology (constellation analysis) promotes exchange and mutual learning across disciplinary boundaries in the context of a junior research group that investigates linkages between mobility and energy in urban areas. Importantly, their work encourages those already engaged in/about to conduct interdisciplinary mobility research to look beyond consensus and to use emerging divergences in conceptual standpoints and methodological orientation to generate fresh insights and advance scientific knowledge. 
The need to recognize and constructively utilize contrasting views and research practices also features prominently in the article by Villeneuve et al. (Contribution 9). Here, the authors, all of whom are members of an interdisciplinary doctoral program in Germany that seeks to promote the advancement of conceptually and methodologically diverse mobility research, reflect upon their experiences in conducting research in this kind of research environment. Drawing on collaborative autoethnography and collective qualitative data analysis, their reflections reveal how aspects of knowledge production that are largely taken for granted in monodisciplinary studies can be crucial to the success (or otherwise) of interdisciplinary efforts. For example, regular opportunities for one-on-one and group interaction resulted in the reconfiguration of interpersonal and intra-group relationships throughout the duration of the doctoral research program. This included mutual recognition and learning but also misunderstandings and conflict over different ontological and methodological positions.

The involvement of diverse civil society actors in mobility research as part of inter- and transdisciplinary projects also receives detailed attention in this special issue (Contribution 10,11). Gebhardt et al. report on a real-world laboratory in a rural setting (Schorndorf, Germany), where a mobility-on-demand bus system was developed and tested as a pilot in an inter- and transdisciplinary inquiry (Contribution 10). It specifically asks how stakeholders can be involved in the research and development process, and in which ways interdisciplinary exchange and joint work at different places can be facilitated. The authors express their support for the application of transdisciplinary research approaches that involve a range of actors, including local residents, and that are capable of capturing the long-term impacts of sustainable transport projects. They conclude with detailed practical recommendations for future interdisciplinary projects at the intersection between research and policy in the transport sector.

Kramar et al. present a mixed-methods approach to urban transport planning that emphasizes the broad involvement of various stakeholders (Contribution 11). The methodological model they develop claims to be holistic in scope. Building on and extending more conventional tools (e.g., SWOT analysis), it permits areas to be ranked according to priorities and the development of scenarios, while at the same time allowing for a better understanding of how to search for compromises when being faced with multiple decision criteria and the need to balance contradictory goals. In sum, this contribution offers a novel methodological tool to facilitate more inclusive and transparent urban transport planning that is capable of reducing the potential for conflict between different societal actors with divergent interests.

Two papers (Contribution 12,13) in particular demonstrate the usefulness of developing innovative research designs that deliberately combine methodological approaches with roots in different disciplines. Serna et al. link two methods to study public bike share systems in Spain (Contribution 12). Firstly, they apply sentiment analysis techniques to user-generated content in social media comments to identify enablers and barriers to the use of bike sharing, identifying five key components in the process. They subsequently use these results to create variables for a statistical model that connects this opinion data with the use of public bike sharing schemes. Their paper aptly demonstrates the benefits of using publicly available data to enhance predictive analytics and demand models in the area of urban bike sharing.

Zarabi et al.'s empirical study complements recent interdisciplinary debates on the complex links between travel mode choice, mode-specific attitudes, and travel-related satisfaction (Contribution 13). Their paper addresses the question of whether and to what extent respondents with a positive attitude towards a certain mode will actually use the mode. In addition, these authors ask if consonant travelers (i.e., those for whom modal attitudes match the mode used) are more satisfied with their trips and travel-related situations compared to their dissonant counterparts. Deviating from the majority of studies in the field, they use a retrospective mixed-method survey that incorporates quantitative and qualitative sections to elicit the mobility-related views of employees who have experienced an involuntary relocation of their workplace. Zarabi et al.'s analysis shows that a combination of levels of accessibility, people's skills and their preferences for other travel attributes such as route influences 
their use of a particular mode (Contribution 13). The paper also shows that travel mode consonance and travel satisfaction are not necessarily positively related. Individuals attribute different weights to their travel attitudes and satisfaction in other life domains can make travel dissatisfaction acceptable.

Overall, the conceptual and methodological richness and diversity of this special issue aptly demonstrate the vast potential of interdisciplinary research on (un)sustainable mobility for producing novel insights and for opening up new avenues of inquiry. In fact, all contributions to this special issue show how interdisciplinary inquiry can foster very fruitful exchanges of ideas and concepts. Challenges arising from efforts to develop a shared understanding of core concepts across disciplinary boundaries and to reconcile competing methodologies and research paradigms are also well covered, offering valuable lessons for future mobility research.

\section{List of Contributions}

1. Johansson, F.; Henriksson, G.; Envall, P. Moving to Private-Car-Restricted and Mobility-Served Neighborhoods: The Unspectacular Workings of a Progressive Mobility Plan.

2. Selzer, S.; Lanzendorf, M. On the Road to Sustainable Urban and Transport Development in the Automobile Society? Traced Narratives of Car-Reduced Neighborhoods.

3. Schwedes, O.; Hoor, M. Integrated Transport Planning: From Supply- to Demand-Oriented Planning. Considering the Benefits.

4. Daramy-Williams, E.; Anable, J.; Grant-Muller, S. Car Use: Intentional, Habitual, or Both? Insights from Anscombe and the Mobility Biography Literature.

5. Jiron, P.; Carrasco, J.A. Understanding Daily Mobility Strategies through Ethnographic, Time Use, and Social Network Lenses.

6. Hidayati, I.; Yamu, C.; Tan, W. The Emergence of Mobility Inequality in Greater Jakarta, Indonesia: A Socio-Spatial Analysis of Path Dependencies in Transport-Land Use Policies.

7. Lejoux, P.; Flipo, A.; Ortar, N.; Ovtracht, N.; Souche-Lecorvec, S.; Stanica, R. Coworking, a Way to Achieve Sustainable Mobility? Designing an Interdisciplinary Research Project.

8. Feldhoff, B.; Stockmann, N.; Fanderl, N.; Gahle, A.-K.; Graf, A.; Leger, M.; Sonnberger, M. Bridging Theories and Practices: Boundary Objects and Constellation Analysis as Vehicles for Interdisciplinary Knowledge Integration.

9. Villeneuve, D.; Durán-Rodas, D.; Ferri, A.; Kuttler, T.; Magelund, J.; Mögele, M.; Nitschke, L.; Servou, E.; Silva, C. What is Interdisciplinarity in Practice? Critical Reflections on Doing Mobility Research in an Intended Interdisciplinary Doctoral Research Group.

10. Gebhardt, L.; Brost, M.; König, A. An Inter- and Transdisciplinary Approach to Developing and Testing a New Sustainable Mobility System.

11. Kramar, U.; Dragan, D.; Topolšek, D. The Holistic Approach to Urban Mobility Planning with a Modified Focus Group, SWOT, and Fuzzy Analytical Hierarchical Process.

12. Serna, A.; Ruiz, T.; Gerrikagoitia, J.K.; Arroyo, R. Identification of Enablers and Barriers for Public Bike Share System Adoption using Social Media and Statistical Models.

13. Zarabi, Z.; Gerber, P.; Lord, S. Travel Satisfaction vs. Life Satisfaction: A Weighted DecisionMaking Approach.

Author Contributions: Conceptualization, H.R. and J.S.; writing-original draft preparation, H.R. and J.S.; writing-review and editing, H.R. and J.S. All authors have read and agreed to the published version of the manuscript.

Funding: This research received no external funding.

Conflicts of Interest: The authors declare no conflict of interest. 


\section{References}

1. Rau, H.; Goggins, G.; Fahy, F. From invisibility to impact: Recognising the scientific and societal relevance of interdisciplinary sustainability research. Res. Policy 2018, 47, 266-276. [CrossRef]

2. Riedel, N.; Köckler, H.; Scheiner, J.; Berger, K. Objective exposure to road traffic noise, noise annoyance, and self-rated poor health-Framing the relationship between noise and health as a matter of multiple stressors and resources in urban neighbourhoods. J. Environ. Plan. Manag. 2015, 58, 336-356. [CrossRef]

3. Gerike, R.; de Nazelle, A.; Wittwer, R.; Parkin, J. Special Issue “Walking and Cycling for better Transport, Health and the Environment". Transp. Res. Part A 2019, 123, 1-6. [CrossRef]

4. Hanson, S. Gender and mobility: New approaches for informing sustainability. Gend. Place Cult. 2010, 17, 5-23. [CrossRef]

5. Uteng, T.P.; Christensen, H.R.; Levin, L. (Eds.) Gendering Smart Mobilities; Routledge: Abingdon, UK, 2020.

6. Vanoutrive, T.; Cooper, E. How just is transportation justice theory? The issues of paternalism and production. Transp. Res. Part A 2019, 122, 112-119. [CrossRef]

7. Verlinghieri, E.; Schwanen, T. Transport and mobility justice: Evolving discussions. J. Transp. Geogr. 2020, 87, 102798. [CrossRef] [PubMed]

8. Morris, E.A. Do cities or suburbs offer higher quality of life? Intrametropolitan location, activity patterns, access, and subjective well-being. Cities 2019, 89, 228-242.

9. Levine, J. A century of evolution of the accessibility concept. Transp. Res. Part D 2020, 83, 102309. [CrossRef]

10. Heisserer, B.; Rau, H. Capturing the consumption of distance? From practice theory to the empirical investigation of everyday travel. J. Consum. Cult. 2015, 17, 579-599. [CrossRef]

11. Holz-Rau, C.; Scheiner, J. Land-use and transport planning-A field of complex cause-impact relationships. Thoughts on transport growth, greenhouse gas emissions and the built environment. Transp. Policy 2019, 74, 127-137. [CrossRef]

12. Rau, H.; Manton, R. Life events and mobility milestones: Advances in mobility biography theory and research. J. Transp. Geogr. 2016, 52, 51-60. [CrossRef]

13. Scheiner, J.; Rau, H. Mobility and Travel Behaviour across the Life Course: Qualitative and Quantitative Approaches; Edward Elgar: Cheltenham, UK; Northampton, MA, USA, 2020; in print.

14. Miles, A.; Moore, N.; Muir, S. Mobility biographies: Studying transport and travel behaviour through life histories. In Strategies for Sustainable Mobilities: Opportunities and Challenges; Hülsmann, F., Ed.; Routledge: London, UK, 2013; pp. 173-188.

Publisher's Note: MDPI stays neutral with regard to jurisdictional claims in published maps and institutional affiliations.

(C) 2020 by the authors. Licensee MDPI, Basel, Switzerland. This article is an open access article distributed under the terms and conditions of the Creative Commons Attribution (CC BY) license (http://creativecommons.org/licenses/by/4.0/). 